\title{
NOVOS RUMOS DO \\ SINDICALISMO NO BRASIL
}

\section{Alexandre Sampaio Ferraz}

\section{Introdução}

Após a redemocratização do país, a discussão sobre o futuro do sindicalismo tomou dois rumos distintos com relação ao impacto das alteraçôes da estrutura sindical sobre a capacidade de organização e ação do movimento sindical. De um lado, os autores que salientam a permanência do "corporativismo estatal" após o fim do autoritarismo; de outro, os autores que enfatizam as mudanças na estrutura sindical em direção a alguma forma de neocorporativismo ou mesmo ao pluralismo. Este artigo analisa as mudanças na estrutura sindical tendo como pano de fundo esse debate.

O corporativismo estatal adotado no Brasil adaptou-se a diferentes regimes e contextos políticos até ser colocado em xeque pelo "novo sindicalismo" e, com a redemocratização, passar por

Aprovado em 08/04/2014 profundas transformações. Ao mesmo tempo que o enquadramento e a contribuição compulsória permanecem como legados do modelo estatal, os freios na intervenção do Estado, a regulamentação das centrais sindicais e as mudanças no cenário político transformaram a dinâmica da disputa no interior da estrutura sindical. Essas mudanças nas regras do jogo têm alterado a dinâmica do sindicalismo, aproximando-a do corporativismo societário.

A desconcentração e a fragmentação na base, herdade da estrutura anterior, foram contrabalanceadas pela concentração na cúpula, com as centrais desempenhando um papel de destaque na definição das políticas públicas deliberadas nas novas instâncias de participação. O princípio da unicidade não evitou a intensa competição nas eleições sindicais nem o desmembramento dos sindicatos, e a competição na cúpula ganhou novo impulso com a regulamentação das centrais. Mesmo assim, as centrais passaram a atuar de modo unificado na defesa 
de bandeiras importantes, como a valorização do salário mínimo e a redução da jornada de trabalho.

\section{O debate sobre o corporativismo}

O corporativismo é um sistema no qual o Estado concede status público aos sindicatos, criando espaços institucionais dentro do aparelho estatal para sua atuação. $\mathrm{Na}$ perspectiva da abordagem corporativista, o poder sindical está ligado às características institucionais do sistema sindical e à existência de canais institucionalizados de acesso ao sistema político decisório (Almeida, 1998, p. 4). No célebre artigo "Ainda o século do Corporativismo?", Schmitter (1974, p. 85) procura afastar do conceito o peso do autoritarismo, bem como dissociá-lo de culturas políticas e tipos de regime singulares, construindo uma "definição operacional" do que chama de um "moderno sistema de representação de interesses". ${ }^{1}$

Schmitter define o corporativismo como um "arranjo institucional" e não um padrão comportamental, criado como alternativa ao pluralismo "para ligar os interesses associativos organizados da sociedade civil às estruturas decisórias do Estado" (Idem, p. 86). Essa "corporativização" do sistema de intermediação de interesse seria uma resposta institucional às "necessidades do capitalismo para reproduzir as condições de sua existência", capaz de assumir características diversas em diferentes fases do capitalismo e contextos políticos (Idem, p. 107).

O corporativismo pode assumir duas formas, estatal e societária, diferenciadas pelo padrão de relação da estrutura sindical com o Estado. No primeiro caso, os sindicatos seriam criados pelo Estado e, no segundo, surgiriam "espontaneamente" da sociedade (Idem, p. 126). Entretanto, a migração do corporativismo estatal para o societário seria difícil devido à "dependência do passado" e ao fato de a sociedade moderna apresentar novas demandas que não "caberiam" nos pressupostos da especialização funcional e da organização hierárquica presentes nas suas duas formas.

Com essa abordagem, Schmitter procura conciliar o corporativismo e a democracia e, assim, criar uma alternativa ao paradigma pluralista para analisar o papel dos grupos de interesse. Em uma crítica a abordagens como a de Claus Offe (1989), o autor argumenta que o corporativismo não é antidemocrático, contra a máxima "cada homem um voto", mas altera a qualidade da democracia: "se alguém procura expandir a noção de igual oportunidade e tratamento políticos para incluir os períodos entre eleições e o processo 'extra' eleitoral, então o corporativismo pode ser interpretado como uma extensão do princípio da cidadania" (Schmitter, 1983, p. 916). ${ }^{2}$

A literatura sobre corporativismo apresenta diversas fissuras em torno das definições do conceito e sua operacionalização. Alguns autores, como Lehmbruch (1977), preferem enfatizar o corporativismo como um padrão institucionalizado de formação de políticas públicas e não apenas de articulação de interesses, caracterizado pela abertura de canais institucionalizados de participação dos sindicatos no processo político decisório. ${ }^{3}$ Entretanto, Schmitter (1982, p. 263) prefere chamar esse fenômeno de "concertação", pois na sua visão o corporativismo é antes um sistema de intermediação de interesses definido pelas propriedades associativas do sistema.

A abordagem do corporativismo, como um padrão distinto de fazer política, atribui grande ênfase à relação estreita entre a ação das lideranças sindicais e partidárias na construção da base legal do sistema e sua crescente institucionalização. $\mathrm{O}$ estabelecimento de "redes corporativas" para as quais é delegado o poder Legislativo em determinadas áreas pressupõe uma "íntima e mútua penetração dos interesses do partido e das organizaçôes" (Lehmbruch, 1984, p. 74). A palavra-chave nessa visão é "concertação", ou consenso ativo, o que presumiria a representação paritária em canais institucionalizados de consulta ao longo do processo decisório, anteriores à deliberação legislativa.

Enquanto nas primeiras pesquisas sobre o corporativismo a preocupação era com a estrutura da organização do sistema de representação de interesse, nas pesquisas posteriores a agenda se concentrou no efeito dessa estrutura sobre o processo de produção e a implementação de políticas públicas. Ao dar esse passo, os trabalhos mostraram que o corporativismo entendido como arranjo institucio- 
nal nem sempre está associado ao corporativismo como padrão de formação de políticas públicas, e que era preciso conhecer melhor o efeito isolado de suas variáveis.

\section{Indicadores de corporativismo}

Os primeiros estudos que procuraram apresentar indicadores mensuráveis de corporativismo trabalharam basicamente com índices compostos que uniam as duas formas de expressão do corporativismo discutidas na seção anterior (Goldthorpe, 1984). Esses indicadores apresentam diversos graus de complexidade, variando da simples classificação binária que opóe o corporativismo ao pluralismo, como em Crouch (1985, p. 117), à criação de índices compostos, ou aqueles que abarcam apenas uma das características do corporativismo (Kenworthy, 2003).

O indicador do grau de "corporativismo societário” formulado por Schmitter (1981, p. 294) é a principal referência dessa fase, e agrega dois outros rankings numa escala de cinco pontos: a) centralização organizacional; b) monopólio associativo. ${ }^{4}$ Este indicador é muito similar ao construído por $\mathrm{Da}$ vid Cameron, chamado "poder organizacional" dos sindicatos. ${ }^{5}$ Mas em vez de se concentrar nas características institucionais e organizacionais do sistema, Cameron (1984) incorpora algumas variáveis conjunturais e de "estilo de agregação de políticas", como a taxa de sindicalização e a representação no sistema político.

Os estudos posteriores tiveram dificuldade de replicar os indicadores de Cameron e Schmitter devido à falta de clareza nas suas definiçóes, levando a uma nova geração de trabalhos que buscaram desagregar os indicadores de corporativismo para sua melhor compreensão (Siaroff, 1999; Kenworthy, 2003). O trabalho de Miriam Golden (1993) é um dos mais consistentes nesta direção, chamando atenção para o fato de que os índices de corporativismo agregam dois conceitos distintos, os de centralização e concentração, e que eles têm impactos diversos sobre o emprego e nem sempre estão associados da mesma maneira.

A centralização mede o grau de "autoridade interna" ao arranjo sindical, o que Cameron cha- ma de "poder das centrais na barganha coletiva" e Schmitter de "centralização organizacional". A centralização avança na medida em que as organizações de cúpula são capazes de controlar os sindicatos através de algum tipo de autoridade, propondo ou vetando greves ou acordos coletivos e recolhendo contribuição dos sindicatos filiados (Golden, 1993, p. 443).

A concentração indica o grau de fragmentação presente no sistema de intermediação de interesse, o que Cameron chama de "unidade organizacional" e Schmitter de "monopólio associativo". Quanto maior a representatividade e menor o número de centrais e sindicatos dentro delas, maior a concentração (Idem, p. 443). O monopólio da representação, legal ou de fato, é fundamental para a concentração, pois restringe a possibilidade de competição entre centrais e sindicatos.

Os dois indicadores buscam captar o grau de coordenação do movimento sindical, que estaria associado à maior capacidade de barganha e à possibilidade da troca "crível" de moderação salarial pela garantia de um baixo nível de desemprego e de outras políticas de bem-estar. A coordenação pode ser atingida tanto pela maior centralização quanto pela maior concentração, entretanto, Golden (1993, p. 451) mostra evidências de que é a maior concentração na estrutura sindical que explica o melhor desempenho econômico, e não as variáveis relacionadas com a centralização ou mesmo com a taxa de sindicalização.

A falta de provas consistentes quanto aos efeitos do corporativismo sobre a economia levou os pesquisadores a se voltarem novamente para a dimensão política do corporativismo, a da participação no processo político decisório (Boreham e Compston, 1992). Compston (1997, p. 723), por exemplo, mostra a "participação sindical no processo político" é "consistentemente associada com a diminuição do desemprego em 13 países da Europa Ocidental" entre 1972 a 1993. Na mesma linha, Kenworthy mostra que "condicionalmente à presença de governo de esquerda, a participação dos sindicatos tende a ser associada ao baixo desemprego nas décadas de 1980 e 1990" (2002, p. 238).

A nova onda de pactos sociais nos anos de 1990 reforçou a abordagem do corporativismo 
como modo de produção de políticas e sua capacidade de oferecer respostas satisfatórias de governança aos governos e ao movimento sindical (Molina e Rhodes, 2002, Siaroff, 1999; Grote e Schmitter, 2008). A presença de pactos em países com baixo grau de corporativismo mostrou também a relevância de novos mecanismos de coordenação pautados no diálogo social (Baccaro, 2003). ${ }^{6}$ Apesar da morte anunciada, o corporativismo encontra-se vivo e ativo.

\section{$O$ poder sindical entre economia e política}

A democracia dissociou o poder de decisão da propriedade dos ativos, possibilitando aos trabalhadores influir na alocação e na distribuição da renda, através da sua atuação na arena política. A criação do mercado político democrático pressupóe, assim, que os capitalistas transfiram parte das decisões sobre o investimento e o gasto para o Estado e para o governo democraticamente eleito. Mas, como mostra Adam Przeworski (1994), nesse sistema a ação do Estado passa a ser limitada estruturalmente pelo fato de sua sobrevivência depender da manutenção do lucro capitalista.

Mesmo que os trabalhadores cheguem a postos decisórios do Estado, devem enfrentar a existência de um trade-off entre o aumento da participação dos salários e a diminuição dos lucros. Isso leva os trabalhadores a colaborar com a manutenção do lucro, enquanto permanecerem sob as regras do capitalismo, garantindo inclusive a própria sobrevivência das organizações sindicais. ${ }^{7}$ A alternativa seria expropriar os capitalistas e eliminar o lucro, mas ela é improvável em função da grande incerteza quanto ao novo sistema a ser implantado.

A possibilidade de melhora do padrão de vida dentro do capitalismo implica que, apesar da dependência estrutural do Estado, há uma margem de manobra para aumentar a taxação sem extinguir os lucros e sem comprometer os investimentos privados. É este aumento da arrecadação que permite ampliar a capacidade de ação do Estado e a adoção de políticas ativas de emprego e outras políticas públicas visando melhorar o padrão de vida dos trabalhadores. A "autonomia" do Estado possibilita que a disputa entre capitalistas e trabalhadores seja vista não como um jogo de soma zero, como querem os liberais ou os marxistas, mas de soma positiva.

Essa abordagem da relação entre capitalismo e democracia abre espaço para o estabelecimento de um pacto racional e mutuamente benéfico entre assalariados e capitalistas (Idem, p. 246). Entretanto, frustrado no campo econômico, onde as partes são claramente desiguais, tal pacto só pode celebrar-se no campo político. Essa perspectiva representa uma ruptura na literatura marxista, que Przeworski (1994) reconstrói em sua análise da social democracia. De um lado, os autores que sustentam a possibilidade da barganha consensual e mutuamente benéfica entre as classes; de outro, aqueles que pensam que qualquer tentativa de barganha esconde a cooptação, a burocratização e o "entreguismo" dos dirigentes sindicais (Offe, 1989).

A disputa de forças entre capitalistas e trabalhadores e o compromisso que emerge da barganha entre as duas classes dependem da posição inicial e da capacidade de coordenação dos "jogadores". A dificuldade intrínseca de coordenação dos trabalhadores os coloca, então, diante de dois jogos simultâneos (Przeworski e Wallerstein, 1988, p 30; Offe e Wiesenthal, 1984). No primeiro, têm que enfrentar o problema da organização, resolvendo o "dilema da ação coletiva". ${ }^{8}$ No segundo, devem barganhar diretamente com o Estado e com os capitalistas por ganhos econômicos e sociais. Nada garante que a solução encontrada pelos trabalhadores no primeiro conduza à maximização dos objetivos no segundo.

O papel ativo do Estado na economia e nas políticas sociais não é, assim, resultado inevitável da democratização e do desenvolvimento capitalista, mas depende da ação dos trabalhadores nessas duas arenas. $\mathrm{O}$ máximo de coordenação seria atingido com a centralização da estrutura em apenas uma organização de cúpula e em uma conjuntura política em que o governo fosse alinhado "exclusivamente" ao movimento sindical. ${ }^{9}$ Nesta situação, concluem Przeworski e Wallerstein (1988, p. 97), o governo "escolherá taxar o consumo capitalista" e reverter este "ganho" para os trabalhadores que 
"receberão benefícios materiais praticamente iguais aos que poderiam obter sob o socialismo". É essa a grande encruzilhada em que se encontra o movimento sindical brasileiro.

\section{Transformações da estrutura sindical no Brasil}

O arranjo corporativista implantado por Getúlio Vargas não criou o movimento sindical, mas seu projeto institucional foi capaz de transformá-lo profundamente. Não foi um modelo pronto, erguido de uma única vez, mas construído a partir de um conjunto de normas que sucederam à criação do Departamento Nacional do Trabalho, em 1931. O legado deste projeto institucional para a cultura do associativismo e consolidação da democracia é ainda hoje objeto de grande controvérsia (Cardoso, 2007; Silva, 2008), assim como os benefícios de sua estrutura para os trabalhadores (Rodrigues, 1990, p. 66; Boito, 1991).

$\mathrm{O}$ arranjo institucional corporativista atribuiu status público aos sindicatos, legitimando-os como representantes dos trabalhadores nas negociações coletivas e impondo a extensão automática dos acordos independentemente da filiação. Mas as regras para concessão da carta sindical e a contribuição compulsória impuseram às entidades um preço alto em termos de subordinação ao governo (Boito, 1991). A contribuição compulsória, embora resolvesse o problema do financiamento dos sindicatos, criou incentivos para ação irresponsável das lideranças perante a base e a criação de sindicatos "de carimbo", sem representatividade. O monopólio legal por categoria profissional de base mínima municipal e o calendário oficial da data-base contribuíram para a constituição de uma estrutura extremamente desconcentrada, descentralizada, que se refletia nas formas de luta (Almeida, 1996; Boito, 1991).

$\mathrm{Na}$ década de 1980, com o advento da abertura democrática e a pressão do "novo sindicalismo", foram realizadas importantes modificaçôes na estrutura sindical, posteriormente incorporadas à Constituição de 1988. Essas alterações introduziram elementos de liberdade democrática, restrin- gindo a intervenção do poder público no funcionamento da organização e permitindo a legalização das centrais. Foram também cristalizados os diretos fundamentais à greve, a autonomia para a vinculação com partidos - ainda que mantida a proibição das doaçôes eleitorais e partidárias -, a liberdade de sindicalização dos trabalhadores do setor público e a filiação voluntária.

A criação das centrais sindicais a partir desse período foi a grande mudança originada no seio do próprio movimento sindical e não na lei, conferindo uma dose de centralismo e de orientação classista ao movimento antes desarticulado (Almeida, 1996). O pluralismo na cúpula passou a conviver com a antiga estrutura corporativa, descentralizada e desconcentrada, e inaugurou um sistema híbrido de intermediação de interesses (Rodrigues, 1990; Almeida, 1996). Entretanto, a virtude do sindicalismo "autônomo" teve seu custo ao negar o reconhecimento legal às entidades, mantendo-as à margem da estrutura corporativista oficial (Almeida, 1996).

A manutenção do monopólio sindical conservou no sindicato de base municipal a exclusividade da representação dos trabalhadores durante a barganha do contrato coletivo de trabalho. Essa prerrogativa pode ser transferida para as organizações de grau superior por delegação prévia do sindicato ou decisão da Justiça do Trabalho, mas não às centrais sindicais. Sem qualquer participação institucionalizada no processo de barganha e participação legal na contribuição sindical, as centrais se viram estruturalmente dependentes da contribuição dos sindicatos associados, particularmente dos "grandes sócios" (Comin, 1994).

Mas a falta de mecanismos de controle sobre os sindicatos foi de certa forma compensada pelo acesso das centrais aos fóruns tripartites oficiais, como representantes legítimas dos trabalhadores. É por via da participação das centrais nesses organismos que os sindicatos realizam a maior parte da sua interlocução com o governo (Idem). Se a autonomia em tese permite aos sindicatos optar ou não por uma das identidades políticas estabelecidas pelas centrais, na prática esses passaram a ter um importante incentivo para a filiação a uma ou outra central. 
Apesar das mudanças no arranjo institucional implantadas com a redemocratização, alguns autores procuram mostrar que a estrutura básica do "sindicalismo de Estado" permanecia intocada. $\mathrm{Na}$ visão de Boito (1991), lembrando as análises de Offe (1989), a estrutura impõe um limite crucial às conquistas dos trabalhadores, contendo a luta sindical no terreno do interesse político da burguesia e separada da luta revolucionária, desorganizando os trabalhadores. Seus reflexos são a atomização, a fragmentação da luta de classe e a submissão do movimento sindical à hegemonia de uma fração de classe, a oligarquia sindical, capaz de manipular a base contra "seus reais interesses".

Apesar de naquele momento ter visto na ligação entre a Central Única dos Trabalhadores (CUT) e o Partido dos Trabalhadores (PT) um indício da superação do sindicalismo populista, posteriormente Boito (1994) chega à conclusão de que todos os que lutaram para a superação do corporativismo estatal foram cooptados pela estrutura do sindicalismo oficial. De um lado, o novo sindicalismo, que outrora de massa e confronto teria rapidamente caminhado para o "neo" corporativismo, passando a agir de forma reativa e a defender posiçôes de cunho "meramente" setorial. De outro lado, os novos atores teriam também abandonado a luta pela liberdade sindical e a adoção da Convenção 87 da Organização Internacional do Trabalho (OIT).

A possibilidade de diferentes interpretaçōes da lei torna ainda mais acirrada a discussão sobre as mudanças normativas na estrutura sindical, principalmente no que diz respeito à liberdade sindical. A nova carta é categórica ao afirmar em seu artigo oitavo que é "livre a associação profissional ou sindical", impedindo o Estado de "exigir autorização para fundação de sindicato", mas derrapa ao exigir o "registro em órgão competente". Aos trabalhadores, por sua vez, foi mantido o princípio da livre filiação aos sindicatos, tal como no período anterior.

A lei maior determina que a "cassação da carta de reconhecimento não imporá o cancelamento do registro" sindical, nem seu fechamento, mas o impede de receber a contribuição sindical e ser o "chancelador" oficial da convenção ou acordo coletivo de trabalho. Nos anos de 1990, a concessão do registro ficou a cargo da Secretaria de Relações de Trabalho do Ministério do Trabalho, mas suas regras passaram recentemente a ser consensuadas no Conselho de Relaçôes de Trabalho (CRT), de natureza tripartite. $\mathrm{O}$ conselho não confere os registros, mas "colabora" na definição das suas regras e aferição das centrais.

A nova carta conferiu maior autonomia ao movimento ao assegurar também o direito de greve, colocando como única restrição a definição, em lei específica, do atendimento das "necessidades inadiáveis da sociedade" em termos de "serviços ou atividades essenciais". ${ }^{10}$ Logo após a promulgação da carta, o governo Sarney tratou de aprovar a Lei 7.783/89, conhecida como a lei de greve do setor privado, em resposta à eclosão de greves no período. No setor público, o direito de greve mereceu um artigo à parte, nunca regulamentado, devendo ser "exercido nos termos e nos limites definidos em lei específica”.

Por fim, o outro elemento importante da liberdade sindical previsto pelo artigo $37 \mathrm{da}$ Constituição é justamente a liberdade de sindicalização do servidor público civil. A ausência da contribuição compulsória, a alta taxa de sindicalização e a capacidade de mobilização fizeram do sindicalismo do setor público o grande exemplo de organização voluntária, reforçando sua legitimidade e aproximando-o da base. ${ }^{11}$ Mas apesar da garantia constitucional da liberdade, o sindicalismo no setor público foi limitado por duas questôes básicas: a regulamentação da greve e da negociação coletiva.

Apenas no governo Lula foi dado um passo objetivo para reverter essa situação, com o envio da PEC 369/2005, que consolidava as demandas do Fórum Nacional do Trabalho (FNT). Mas se a adesão à Convenção 151 da OIT e a decisão do Supremo Tribunal Federal (STF) de aplicar as regras do setor privado para as greves do setor público até a sua regulamentação reforçaram a necessidade de regulamentação da matéria, as resistências dentro da burocracia estatal - questionando a constitucionalidade da negociação no setor público e a falta de acordo entre sindicatos de servidores e centrais quanto à inclusão de regras de unicidade, representatividade e contribuição sindical no projeto - tem contribuído para retardar esse processo. 


\section{A movimentação na cúpula}

A CUT foi a primeira central criada sob a bandeira do "novo sindicalismo", em 1983, mantendo desde o início estreitos vínculos com o PT. O discurso contrário ao corporativismo estatal, ao imposto sindical e pela liberdade sindical, juntamente com uma estratégia combativa e a recusa dos pactos sociais nos anos de 1980, contribuíram para o fortalecimento da central. Tal fato contrastava com a adoção de uma estratégia pragmática de conquista das entidades oficiais pela via eleitoral e de mobilização política nos novos canais legislativos abertos com a redemocratização (Almeida, 1996). Noronha (2000) mostra a centralidade da arena legislativa para os sindicatos após a redemocratização e diante do nosso sistema "legislado" de relaçôes de trabalho.

Ainda em 1985, seria criada também a União Sindical Independente (USI), com predomínio de sindicatos ligados ao comércio. E no ano seguinte, a Central Geral dos Trabalhadores (CGT), aglutinando membros da estrutura oficial ligados aos partidos MR-8, PCB, PMDB e PCdoB. Enquanto na fundação da CUT havia a presença significativa de funcionários públicos e sindicatos rurais, a CGT apresentava um grande número de federações e confederaçóes da estrutura oficial, o que contribuiu para que a nova CGT herdasse as posiçōes da velha CGT, pela manutenção do imposto sindical e a recusa da liberdade nos moldes da Convenção 87 da OIT (Santana e Braga, 2009).

A década de 1980 foi marcada pela explosão do número de greves e também de novos sindicatos, ajudando a legitimar o movimento dos trabalhadores que se revitalizava com a redemocratização (Noronha, 2009; IBGE, 2003). Mas a atividade grevista na base contrastou com a baixa capacidade de influência das centrais nos governos Figueiredo e Sarney, não se traduzindo na "construção de canais de influência sobre políticas de governo" (Almeida, 1998, p. 351). Entretanto, o fracasso dos planos de estabilização e a articulação de greves nacionais foram aos poucos legitimando as centrais como interlocutoras dos trabalhadores na construção de pactos sociais.

A Central Geral dos Trabalhadores buscou preencher esses novos espaços, colocando-se como interlocutora da classe trabalhadora junto ao empresariado e ao governo. Seria a origem do "sindicalismo de resultados", erguido em contraposição à estratégia de confronto adotada pela CUT. Neste período, a CGT acabaria "rachando", com a saída dos membros ligados ao MR-8 e ao PCB para criar a atual Confederação Geral dos Trabalhadores do Brasil (CGTB).

Entre 1988 e 1989, sindicalistas ligados aos partidos PCB, PCdoB e PSB também sairiam da CGT para ingressar na CUT alguns anos depois. Mas foi em 1992 que um novo racha na CGT, liderado pelo Sindicato dos Metalúrgicos de Sáo Paulo, deu origem à segunda maior central do país, a Força Sindical (FS). Esta ganhou espaço dentro do movimento sindical com um discurso de contraposição à CUT, buscando aproximar-se do governo em defesa das reformas neoliberais. Essa linha de atuação contribuiu inclusive para que a entidade ganhasse a eleição em importantes sindicatos cutistas ligados às empresas privatizadas (Boito, 1999).

As alterações na cúpula continuariam na década de 1990 com a criação da Central Autônoma dos Trabalhadores (CAT), em 1994., e da Social Democracia Sindical (SDS), em 1996, com dissidentes da FS e apoio político do PSDB. A influência da competição partidária foi decisiva na disputa entre as centrais e mesmo nas disputas internas, o que levou Rodrigues (1991) e Almeida (1996) a atribuírem esse movimento de criação e fusão de centrais mais à atuação das elites sindicais no campo partidário do que uma adesão explícita ao pluralismo sindical. ${ }^{12}$ Além disso, diversos dirigentes passaram para carreira política ou para cargos na gestão pública.

A movimentação na cúpula continuou na década seguinte com o surgimento de quatro novas centrais. O contexto político marcado pela reforma da previdência, pelo Fórum Nacional do Trabalho (FNT) e por escândalos de corrupção contribuiu para que, em 2004, grupos ligados ao Partido Socialista dos Trabalhadores Unificado (PSTU) e à corrente Intersindical saíssem da CUT para fundar a Consultas. Em 2007, a CUT perderia também a Corrente Sindical Classista, ligada ao PC do B, que fundaria a Central dos Trabalhadores do Brasil (CTB). 
Os conflitos ocorridos durante o FNT levaram, ainda, à criação da Nova Central Sindical dos Trabalhadores (NCST), em 2005, reunindo as confederaçôes oficiais. Por fim, em 2007, foi criada a União Geral dos Trabalhadores (UGT), com a fusão de CAT, SDS e CGT e a incorporação de dissidentes da Força Sindical. Mas apesar desse conflito latente em torno da estrutura sindical, a partir do governo Lula as centrais foram capazes de construir uma unidade de ação e uma importante pauta nacional conjunta, em grande parte mediada pelo Dieese (Radermacher e Melleiro, 2007).

Essas mudanças na cúpula ocorreram no bojo da consolidação e da institucionalização das centrais no governo Lula. A legalização das centrais materializou-se por meio do PL 1997/2007 de autoria do Executivo e relatoria do deputado Vicentinho (PT-SP), após o fracasso da Medida Provisória 239/2006. Sua redação apresentava duas diferenças importantes em relação ao texto da MP, abrandando os critérios para determinar a representatividade das centrais - de $10 \%$ para $7 \%$ dos trabalhadores sindicalizados no país - e conferindo às centrais uma parte dos recursos da contribuição sindical.

No texto da Lei $11.648 / 08$, o Legislativo rejeitou a brecha para que as centrais assumissem o papel dos sindicatos ao mudar a redação inicial do artigo primeiro pelo qual elas teriam a prerrogativa de "exercer a representação dos trabalhadores", para "coordenar a representação". O poder Executivo, por sua vez, vetou a regra que obrigava as centrais a prestarem contas ao Tribunal de Contas da União.

A lei formalizou o papel das centrais de representante dos trabalhadores no plano nacional através da negociação em "fóruns, colegiados de órgãos públicos e demais espaços de diálogo que possuam composição tripartite". Tal posição consolidou a atuação que já era de fato exercida pelas entidades e que encontra respaldo no artigo 10 da Constituição que assegura "a participação dos trabalhadores e empregadores nos colegiados dos órgãos públicos em que seus interesses profissionais ou previdenciários sejam objeto de discussão ou deliberação". Ao Ministério do Trabalho coube a criação do índice de representatividade das centrais, a ser usado para definir a proporção de vagas de cada central nos fóruns tripartites, "salvo em caso de acordo entre elas".
No que toca à contribuição sindical, prevaleceu a tese de que os sindicatos têm a liberdade de filiação às centrais, decidindo para qual será revertida a contribuição e abrindo uma brecha para a sua substituição pela "contribuição negocial", nos moldes defendidos pela CUT. A alteração da CLT promovida pelo texto final destinou às centrais $10 \% \mathrm{da}$ contribuição sindical, em prejuízo da conta "Emprego especial, emprego e salário". Assim, o próprio governo absorveu a perda de arrecadação, em vez de impor custos à estrutura existente, dissipando as resistências que poderiam surgir. Mas não evitou que o interesse pelos recursos acirrasse a disputa na cúpula por sindicatos.

\section{As novas instâncias de participação}

A participação das centrais sindicais em fóruns tripartites ganhou um novo caráter com a Constituição de 1988. O governo Sarney foi permeado por tentativas frustradas de pacto social envolvendo as centrais, devido em grande parte à debilidade do movimento sindical e do próprio governo e de uma marcada estratégia de confronto por parte da CUT. As tentativas de pacto social e negociação tripartite foram retomadas no governo Collor com a criação dos "grupos executivos de políticas setoriais" e posteriormente o Fórum Capital Trabalho, reunindo pela primeira vez as três maiores centrais. Mas foi a "câmara setorial automotiva", no governo Itamar, que teve o maior êxito entre essas iniciativas. $\mathrm{O}$ próprio caráter tripartite da câmara foi introduzido na lei por iniciativa de um deputado do PT ligado à CUT, Aluisio Mercadante (Martin, 1996).

Esse experimento de diálogo social foi esvaziado no governo Cardoso, mas deixou uma marca expressiva no movimento sindical (Santana e Braga, 2009; Ramalho e Rodrigues, 2010). As interpretaçōes dessa experiência na literatura podem ser divididas em dois grupos: de um lado, os autores que viam nas câmaras o embrião de sucesso do que poderia ser o estabelecimento de "corporativismo societário" no país (Martin, 1996), ${ }^{13}$ de outro, os que criticaram a experiência como manifestação de um tipo de neocorporativismo setorial, egoísta por natureza, que desvia os trabalhadores da luta por "transformações estruturais" e legitima a política neoliberal (Boito, 1999). ${ }^{14}$ 
As origens dessa nova face participacionista e propositiva do sindicalismo estão intimamente vinculadas ao pacto constitucional de 1988. Aos poucos os sindicatos foram ocupando os novos espaços democráticos, seja pela pressão direta dos poderes Executivo e Legislativo, seja pela participação institucionalizada nas novas instâncias tripartites. A Constituição consagrou os princípios da participação popular e das organizações dos trabalhadores no processo legislativo e na administração pública - áreas das políticas previdenciária, agrícola, seguridade social, saúde e assistência social. Esses dispositivos permitiram a criação de muitos conselhos consultivos, deliberativos e fiscais, que procuram aumentar o controle e a transparência da administração pública e influenciar o rumo das políticas públicas.

As centrais sindicais, mesmo antes de sua legalização oficial, passaram a atuar em conselhos importantes criados após 1990, como o Conselho Nacional de Previdência Social (CNPS), o Conselho Deliberativo do Fundo de Amparo ao Trabalhador (Codefat) e o Conselho Curador do Fundo de Garantia por Tempo de Serviço (CCFGTS). ${ }^{15}$ Esses conselhos deliberam sobre algumas das políticas públicas mais importantes para os trabalhadores e movimentam orçamentos vultosos. Apenas o FAT e o FGTS, duas das principais fontes de financiamento do desenvolvimento do país, tinham em 2012 um patrimônio conjunto de R 529 bilhôes ou $12 \%$ do PIB.

No governo Lula ampliaram-se essas novas arenas e foram criados novos conselhos, como o Conselho Nacional de Economia Solidária (CNES) e o Conselho de Desenvolvimento Econômico e Social (CDES). Também foi regulamentada a participação dos trabalhadores nos conselhos das empresas estatais e de economia mista e foram criadas outras instâncias de duração determinada - as conferências -, onde se discutiram pontos específicos da agenda sindical e governista. Três destas foram particularmente importantes para o movimento sindical: 1) o Fórum Nacional do Trabalho (FNT); 2) a Comissão de Valorização do Salário Mínimo, responsável por uma política de valorização do salário mínimo, vinculando-o ao crescimento do PIB e à inflação; ${ }^{16}$ 3) o Fórum Nacional de Previdência Social.
O FNT evidenciou a face consociativa do governo Lula. A tentativa de formular uma proposta de reforma trabalhista e sindical a partir da criação de uma comissão tripartite justificava-se pela especificidade dos interesses envolvidos e pelo alto grau de resistência tanto por parte dos sindicatos dos trabalhadores quanto dos empresários. No lado dos trabalhadores, a CUT e a Força Sindical dividiram o comando das plenárias e das comissóes, convergindo na maior parte das questões, mas sem a adesão das demais centrais (Almeida, 2007).

No texto final, que acabou sem apoio consensual, ficou determinado que o imposto sindical seria gradualmente extinto e substituído pela "contribuição negocial" e que as centrais deveriam ser legalizadas. As reformas propostas foram divididas em dois blocos: a reforma trabalhista, propriamente dita, e a reforma sindical. O primeiro resultou na Proposta de Emenda Constitucional n. 369/05, que altera a redação do capítulo sobre liberdade sindical e cria a representação no local de trabalho. O segundo, no "Anteprojeto de Lei de Relações Sindicais" que regulamenta as centrais sindicais, cria o Conselho Nacional de Relações de Trabalho e reorganiza o financiamento do sistema.

A participação dos sindicatos nos fóruns tripartites não se limitou a essas esferas, estendendo-se a uma multiplicidade de novas arenas, como os conselhos das cidades, da saúde, da educação e do "Sistema S". Na esfera federal, havia 32 conselhos e duas comissões nacionais, até 2010, sendo que 18 foram criados no governo Lula e outros 15, reformados (Brasil, 2010). Ao menos 19 desses conselhos e comissões têm participação direta do movimento sindical. No seu conjunto, esses fóruns têm definido aspectos importantes das políticas públicas, particularmente após o governo Lula, e possibilitado o exercício do controle social das políticas e recursos (Pogrebinschi e Santos, 2011).

O aprofundamento dessa participação tem permitido aos sindicatos um aprendizado a respeito da elaboração de políticas públicas, que os coloca em um novo patamar no debate sobre os rumos do Estado e da economia (Comin, 1994, p. 389; Santana e Braga, 2009). Além disso, contribui para cristalizar o caráter consociativo da democracia brasileira na sua interface com o corporativismo, aqui como modo de "fazer política". A permanência de 
um governo liderado por um partido de esquerda e próximo aos sindicatos no poder foi fundamental nessa construção, fato reforçado pela aposta do governo Dilma Rousseff na arquitetura de uma nova política industrial pactuada a partir das Comissóes Sistêmicas do Plano Brasil Maior.

\section{O sindicalismo está morto?}

$\mathrm{Na}$ década de 1990, o sindicalismo passou por uma crise que tem fundamentos tanto teóricos quanto empíricos. O destino do sindicalismo estava marcado pelo declínio do seu poder - não só de uma perspectiva institucional, mas também política, com a queda do número e da proporção de trabalhadores filiados - e o declínio das taxas de greve (Rodrigues, 2002). Entretanto, alguns autores procuraram mostrar sinais de persistência nas organizações sindicais e na sua importância políti$\mathrm{ca}$, afirmando que em alguns casos esta "sobrevida" se dava em um patamar mais alto de concentração (Golden, Wallerstein e Lange, 1999).

$\mathrm{O}$ corporativismo não é imune às mudanças tecnológicas na produção e no mercado de trabalho, nem aos ciclos econômicos e às alteraçōes no equilíbrio de forças na arena política. Se é verdade que diante dessas alterações o movimento sindical brasileiro tem sido "prisioneiro do passado", também é verdade que tem sido capaz de usar e alterar a estrutura, ao longo dos anos, para acomodar seus interesses e se fortalecer. Apesar de ter tido sua morte decretada, o sindicalismo tem mostrado que está vivo e mais forte do que se esperava.

Não foi fácil superar a década de 1990, quando o emprego formal divulgado pelo Ministério do Trabalho apresentou uma tendência de queda e a taxa de desemprego calculada pelo IBGE subiu de forma praticamente constante. $\mathrm{O}$ resultado foi um aumento da informalidade nas regiōes metropolitanas, entre 1992 e 2002, coincidindo com a estagnação do PIB per capita e a queda contínua do rendimento médio dos ocupados, entre 1996 e 2003 (Ipea, 2013). Mas, apesar desse cenário, o sindicalismo parece ter se fortalecido.

Os dados do IBGE (2003) mostram que o número de sindicatos dos trabalhadores cresceu
$49,2 \%$ entre 1992 e 2001 , chegando a 11.354 . Tal crescimento implicou maior fragmentação, mas revelou também uma grande capacidade de mobilização dos trabalhadores (Cardoso, 1997). No mesmo período, 3,5 milhões de "novos" trabalhadores urbanos se sindicalizaram, elevando para 9,2 milhões o número de sindicalizados, dos quais $66,5 \%$ estavam sob o guarda-chuva das centrais.

O crescimento na base foi acompanhado de maior concentração na cúpula, com o aumento dos sindicatos filiados às centrais, que passou de $33 \%$ para $38 \%$. Ao mesmo tempo, as duas principais centrais mantiveram sua hegemonia, com mais de $86 \%$ do total das filiações sindicais ao longo do período. Em 2001, os sindicatos filiados a centrais respondiam por $52,3 \%$ do total de trabalhadores filiados $(66,5 \%$ no caso dos empregados urbanos), sendo que as duas primeiras centrais concentravam mais de $88 \%$ desses trabalhadores. O próprio IBGE (2003, p. 80), na análise do censo sindical, conclui que: "Levando-se em conta que houve um expressivo aumento do número absoluto de sindicatos na última década, conclui-se que as centrais sindicais fortaleceram-se bastante".

Apesar de não serem comparáveis aos dados do IBGE, os dados do Ministério do Trabalho e Emprego mostram que no início de 2010 havia 8.826 sindicatos urbanos com carta sindical, contra 6.133 no censo de 2001. Em 2010, 61,3\% dos sindicatos eram filiados a alguma central, contra os $38 \%$ de 2001 . Em março de 2012, o total de entidades registradas havia passado para 9.854 , sendo $72,9 \%$ filiadas a centrais. Este crescimento veio acompanhado de uma nova realidade no mercado de trabalho, marcada pelo crescimento expressivo do emprego formal. Entre 2003 e 2012, o emprego formal registrado na Rais/MTE cresceu $60 \%$, contra os $24 \%$ no período anterior.

A Tabela 1 apresenta o índice de representatividade das centrais calculado pelo Ministério do Trabalho. ${ }^{17}$ Nela é possível observar um quadro de relativa estabilidade na representatividade das centrais, apesar do pluralismo e da competição na cúpula. Também é possível observar o aumento do volume da contribuição sindical destinada às centrais, um movimento que deve ser explicado pelo aumento da participação de sindicatos filiados, mas também pelo crescimento do emprego formal e da renda. 
Tabela 1

Índice de Representatividade das Centrais (\%) e Valor da Contribuiçáo Sindical (R\$ Milhóes)

\begin{tabular}{llllllll}
\hline Central & $\mathbf{2 0 0 8}$ & $\mathbf{2 0 0 9}$ & $\mathbf{2 0 1 0}$ & $\mathbf{2 0 1 1}$ & $\mathbf{2 0 1 2}$ & $\mathbf{2 0 1 3}$ & $\mathbf{2 0 1 4}$ \\
\hline CUT & 35,8 & 36,8 & 38,2 & 38,3 & 36,7 & 35,6 & 34,4 \\
\hline FS & 12,3 & 13,1 & 13,7 & 14,1 & 13,7 & 13,8 & 12,6 \\
\hline UGT & 6,3 & 7,2 & 7,2 & 7,9 & 11,3 & 11,2 & 11,9 \\
\hline CTB & 5,1 & 6,1 & 7,6 & 7,8 & 9,2 & 9,2 & 9,3 \\
\hline NCST & 6,3 & 5,5 & 6,7 & 7,0 & 8,1 & 8,1 & 8,0 \\
\hline CGTB & 5,0 & 5,0 & 5,0 & 7,0 & - & - & - \\
\hline Total & 70,8 & 73,7 & 78,4 & 82,2 & 79,0 & 77,9 & 72,6 \\
\hline Três maiores & 54,46 & 57,08 & 59,13 & 60,33 & 61,7 & 60,6 & 58,9 \\
\hline Contribuição Sindical* & 65,7 & 81,0 & 102,3 & 124,6 & 141,7 & 161,9 & \\
\hline
\end{tabular}

* Boletim de Informaçôes Financeiras do Fundo de Amparo ao Trabalhador - FAT/MTE.

Fonte: Ministério do Trabalho e Emprego. Disponível em http://portal.mte.gov.br/portal-mte/relacoes-de-trabalho/ consulta-afericao-de-central-sindical/.

Os dados de 2011 mostram que UGT, CGTB e NCST estavam próximas do limite mínimo para receber o repasse, de $7 \%$ de trabalhadores. Em 2011, contudo, a CRT definiu que o novo cálculo levaria em conta a declaração do número de filiados que consta das atas de votação nas eleições sindicais e montou uma comissão intersindical para apurá-lo. O resultado foi que em 2012 a CGTB não atingiu o índice, mas manteve seu status público oficial, o direito aos recursos da contribuição e a participação nos conselhos federais graças a uma decisão judicial, cujo mérito ainda não foi julgado.

$\mathrm{Na}$ luta para superar o índice mínimo de representatividade e receber o imposto sindical e assento nos fóruns tripartites, é possível que ocorram novas movimentações na cúpula, com a fusão das centrais existentes. ${ }^{18}$ Entretanto, os dados permitem observar que há uma grande concentração do movimento sindical na CUT e na Força, apesar do grande número de centrais. ${ }^{19} \mathrm{~A}$ maior porcentagem de sindicatos ligados às centrais parece qualificar a concentração na cúpula, movimento que foi estimulado pela vinculação da receita com a contribuição sindical à filiação dos sindicatos na base.

O valor repassado, por sua vez, tem permitido às centrais profissionalizar e estruturar suas organi- zações tanto para preencher os novos espaços institucionais quanto para levar adiante a disputa com a patronal, bem como a disputa interna ao movimento. O julgamento da Adin 4.067 pelo Supremo Tribunal Federal deve resolver se o repasse é legal ou não, em uma votação que segue empatada. Caso o repasse seja revertido, as centrais devem encontrar uma grande dificuldade financeira e ter reduzida sua capacidade de ocupar os espaços tripartites.

\section{Perspectivas para a próxima década}

O sindicalismo parece novamente se encontrar em uma encruzilhada. Antigos debates sobre a autonomia sindical permanecem, como a cobrança do imposto sindical e a adoção da Convenção 87 da OIT. Outros ganharam novo fôlego, como a concessão da carta sindical e o enquadramento sindical, a regulamentação da contribuição sindical e dos direitos de greve e a negociação no setor público. Particularmente no setor público, as definições podem favorecer maior fragmentação, levando a uma corrida pelo registro e pela contribuição sindical. Mas também podem dar ao sindicalismo do setor público maior capacidade de mobilização, o 
que trará implicações de longo prazo para o balanço de poder entre os sindicatos dos setores público e privado dentro das centrais sindicais.

Ao mesmo tempo, o movimento sindical deve buscar a consolidação das conquistas obtidas durante o governo Lula no que toca à presença dos sindicatos nas novas arenas de participação, a política de valorização do salário mínimo e de crescimento do emprego. No caso da participação nos conselhos de políticas públicas, como o Codefat, o CCFGTS e o CNPS, em que a presença sindical já está de certa forma consolidada, o movimento sindical pode vir a observar uma batalha entre as centrais pela participação, em decorrência do cumprimento da Lei 11.648/2008.

As modificaçōes em curso parecem nos aproximar cada vez mais do corporativismo societário, contrariando o cenário dos anos de 1990, quando o pluralismo parecia plausível (Almeida, 1998). O toque menos "míope" e mais classista parece ter sido dado pelo amadurecimento das centrais, ao contrário do que se viu até a estabilização econômica (Almeida, 1996, p. 197). Ainda que a sobrevivência de certas características do arranjo anterior não contribua para a maior coordenação e centralização do movimento sindical, as novas regras para centrais parecem ter modificado a dinâmica da disputa na cúpula, favorecendo a concentração e a coordenação.

Se o pluralismo parece distante e improvável, a permanência do corporativismo estatal ou sua migração para um modelo societário deve ser vista dentro do jogo de forças que atuou no Fórum do Trabalho e resulta da cristalização de interesses e da fragmentação política, mais do que da intenção do Estado. O projeto institucional dos criadores do arranjo corporativista brasileiro ganhou vida própria e as organizaçôes sindicais voltam a ensaiar sua emancipação sem, no entanto, andar no sentido do pluralismo e do abandono do status público.

\section{Notas}

1 Segundo Schmitter, o corporativismo é um sistema de intermediação de interesse, "no qual as unidades constituintes são organizadas num número limitado de categorias singulares, compulsórias, não competitivas, hierarquicamente ordenadas e funcionalmente diferenciadas, reconhecidas e permitidas (se não criadas) pelo Estado, às quais se outorga o monopólio de uma representação deliberada no interior das respectivas categorias em troca da observância de certos controles na seleção de seus líderes e na articulação de suas demandas e apoios" (1974, pp. 93-94).

2 Offe (1989) afirma que o corporativismo não pode ser legitimado democraticamente e chama atenção para os efeitos negativos da atribuição de status público: burocratização, irresponsabilidade, oportunismo.

3 Lehmbruch define o corporativismo como um "padrão institucionalizado de formação de políticas no qual grandes organizaçóes de interesses cooperam umas com as outras e com as autoridades públicas não apenas na articulação (ou mesmo intermediação) de interesses, mas na alocação oficial de valores e na implementação dessas políticas" (1977, p. 94).

4 O primeiro agrega quatro variáveis indicando o poder das centrais sobre seus filiados (participação na barganha coletiva; fundos de greve; staff próprio; cobrança de contribuição). O segundo agrega três variáveis organizacionais (número de centrais; abrangência; existência de facções internas nas centrais).

5 O índice de Cameron (1984, p. 164) agrega cinco variáveis: 1) taxa de sindicalização; 2) estrutura organizacional (número de centrais e de sindicatos); 3) poder das centrais na barganha coletiva (fundos de greve, veto sobre acordos e greves); 4) escopo da barganha coletiva; 5) existência de canais institucionalizados de representação no sistema político.

6 "Mesmo estruturas sindicais relativamente fragmentadas podem encontrar formas alternativas e mais democráticas de coordenação em apoio a processos políticos concertados" (Baccaro, 2003, p. 700).

7 Como observa Rodrigues: "Os sindicatos, para garantir sua sobrevivência, devem ser antipatronais, mas não anticapitalista [...] o limite do poder sindical é a sobrevivência da empresa" (1990, p. 44).

8 Wallerstein (1989) mostra que a centralização representa um padrão específico de coalizão de classe, alicerçada na barganha por políticas sociais, mas que outra conjuntura poderia favorecer coalizões setoriais e a demanda por políticas protecionistas.

9 A associação entre o poder organizacional dos trabalhadores e o controle do governo por partidos de esquerda é fundamental nesta literatura (Cameron, 1984; Lipset e Katchanovski, 2000). 
10 Segundo o art. 9 da Constituição: "É assegurado o direito de greve, competindo aos trabalhadores decidir sobre a oportunidade de exercê-lo e sobre os interesses que devam por meio dele defender. $\$ 1^{\circ}$ A lei definirá os serviços ou atividades essenciais [...]. \$2 $\$ 2^{\circ}$ Os abusos cometidos sujeitam os responsáveis às penas da lei”.

11 Em 2008, o Ministério do Trabalho e Emprego publicou uma "Instrução Normativa" regulamentando a contribuição sindical do setor, que vem sendo questionada juridicamente.

12 Radermacher e Melleiro (2007) observam o mesmo fenômeno, mas ao contrário do que procuramos mostrar, associam este movimento a um enfraquecimento das duas principais centrais.

13 Antunes (1993, p. 90) mostra como a corrente Articulação da CUT passou no decorrer do tempo a adotar uma postura marcadamente social-democrata, em prol da negociação e em oposição às posturas socialistas ou anticapitalistas.

14 Para Boito, as câmaras foram, em relação à estratégia sindical dos anos de 1980, "um retrocesso político, ou um movimento específico de despolitização do sindicalismo [...] esse novo corporativismo [...] é, em face dos trabalhadores [...] uma estrutura de dominação e não [...] de representação de interesses" (1999, p. 168). Para uma crítica do "sindicalismo colaborativo", ver também Alves (2000).

15 A participação das centrais no Fundo de Amparo ao Trabalhador (FAT) abriu caminho também para sua participação no conselho do BNDES, que tem como fonte de recurso $40 \%$ da receita com o PIS/Pasep.

16 Esta política iniciada em 2006 foi estendida, no governo Dilma Rousseff (Lei 12.392/2011), até 2019.

$17 \mathrm{O}$ índice de representatividade é calculado com base na Portaria 194/2008, em cumprimento à Lei $11.648 / 2008$, dividindo-se o total de trabalhadores filiados aos sindicatos integrantes da central pelo total de trabalhadores filiados em âmbito nacional, segundo dados da Rais.

18 Do ponto de vista da lógica das ligaçôes internacionais, as fusões podem unir as centrais CTB e CGTB, ambas filiadas à Federação Sindical Mundial, e CUT, FS e UGT, filiadas à Confederação Sindical Internacional.

19 Fora a CGTB, havia em 2012 outras seis centrais cadastradas no MTE e que não atingiram o mínimo necessário por lei, representando pouco mais de 700 sindicatos.

\section{BIBLIOGRAFIA}

ALMEIDA, Gelsom (2007), “O governo Lula, o Fórum Nacional do Trabalho e a reforma sindical”. Katál, 10 (1): 54-60.

ALMEIDA, Maria H. T. (1996), Crise econômica e interesses organizados. São Paulo, Edusp.

. (1998), "Sindicatos em tempos de reforma”. São Paulo em Perspectiva, 12 (1): 3-9.

ALVES, Giovanni. (2000), "Do "novo sindicalismo" à "concertação social": ascensão (e crise) do sindicalismo no Brasil (1978-1998). Revista de Sociologia e Política, 15: 111-124.

ANTUNES, Ricardo (1993). "A CUT entre o classismo e a socialdemocracia", in Sebastião Neto e Vito Giannotti (org.), Para onde vai a CUT? Campinas, Scritta.

BACCARO, Lucio. (2003), "What is alive and what is dead in the theory of corporatism". British Journal of Industrial Relations, 41 (4): 683-706.

BOITO, Armando. (1991), O sindicalismo de estado no Brasil. São Paulo, Editora da Unicamp/ Hucitec.

(1994), "De volta para o novo corporativismo: a trajetória política do sindicalismo brasileiro”. São Paulo em Perspectiva, 8 (3): 23-28.

. (1999), Politica neoliberal e sindicalismo no Brasil. 2. ed. São Paulo, Xamã.

BOREHAM, Paul \& COMPSTON, Hugh. (1992), "Labour movement organization and political intervention: the politics of unemployment in the OECD countries, 19741986". European Journal of Political Research, 22: $143-170$.

BRASIL. (2010), Conselhos nacionais. Secretaria-Geral da Presidência da República/Secretaria Nacional de Articulação Social, Imprensa Nacional.

CAMERON, David. (1984), "Societal democracy, corporatism, labour quiescence, and the representation of economic interest in advanced capitalist society", in J. Goldthorpe (org.), Order and conflict in contemporary capitalism, Oxford, Oxford University Press.

CARDOSO, Adalberto. (1997), "O sindicalismo corporativo não é mais o mesmo”. Novos Estudos Cebrap, 48: 97-119. 
(2007), "Estado Novo e corporativismo". Locus: Revista de História, 13 (2): 109-118, Juiz de Fora.

COMIN, Álvaro (1994), "A experiência de organização das centrais sindicais no Brasil", in C. A. B. Oliveira, M. A. Oliveira e J. Mattoso (orgs.), O Mundo do trabalho: crise e mudanças no final do século XX. São Paulo, Scritta.

COMPSTON, Hugh. (1997), "Unions power, policy-making and unemployment in Western Europe, 1972-1993". Comparative Political Studies, 30 (6): 732-751.

CROUCH, Colin. (1985), "Conditions for trade union restraint”, in L. Lindberg e C. Maier (orgs.), The politics of inflation and economic stagnation, Washington, DC, Brookings Institution.

GOLDEN, Miriam. (1993), “The dynamics of trade unionism and national economic performance". American Political Science Review, 87 (2): 439-454.

GOLDEN, Miriam A.; WALLERSTEIN, Michael \& LANGE, Peter. (1999), "Postwar Trade-Union Organization and industrial relations in twelve countries", in H. Kitschelt, P. Lange, G. Marks e J. Stephens (eds.), Continuity and change in contemporary capitalism. Nova York, Cambridge University Press.

GOLDTHORPE, John. (1984), "The end of convergence: corporatist and dualist tendencies in modern Western societies", in John H. Goldthorpe (ed.), Order and conflict in contemporary capitalism: studies in the political economy of Western European nations, Oxford, Oxford University Press.

GROTE, Jüger \& SCHMITTER, Philippe. (2008), "O resnascimento do corporatismo nacional”, in Jorge Tapia, Eduardo Gomes e Eduardo S. Condé (orgs.), Pactos sociais, globalização e integração nacional. Campinas, Editora da Unicamp.

IBGE. (2003), "Sindicatos: indicadores sociais 2001". Rio de Janeiro, Departamento de População e Indicadores Sociais, IBGE.

IPEA (2013), "Um retrato de duas décadas do mercado de trabalho brasileiro utilizando a PNAD”. Comunicados do Ipea, 160.
KENWORTHY, Lane. (2002), "Corporatism and unemployment in the 1980s and 1990s". American Sociological Review, 67: 367-388.

(2003), "Quantitative indicators of corporatism”. International Journal of Sociology, 33: 10-40.

LEHMBRUCH GERARD. (1977), "Liberal corporatism and party government". Comparative Political Studies, 10 (1): 91-126

. (1984), "Concertation and structure of corporatist networks", in J. Goldthorpe (ed.), Order and conflict in contemporary capitalism, Oxford, Oxford University Press.

LIPSET, Seymour \& KATCHANOVSKI, Ivan. (2000), "Corporatism, left government and union density in advanced Western countries". Trabalho apresentado no World Congress of the International Political Science Association, Quebec City, ago., 1-5.

MARTIN, Scott. (1996), "As câmaras setoriais e o meso-corporativismo". Lua Nova, 37: 139-170.

MOLINA, Oscar \& RHODES, Martin. (2002), "Coportatism: the past, present, and future of a concept”. Annual Review. Political. Science, 5: 305-331.

NORONHA, Eduardo G. (2000), "O modelo legislado de relações de trabalho no Brasil". Dados [online], 43 (2).

. (2009), "Ciclo de greves, transição política e estabilização: Brasil 1978-2007". Lua Nova, 76: 119-168.

OFFE, Claus. (1989), "A atribuição de status público aos grupos de interesse", in lismo desorganizado. São Paulo, Brasiliense.

OFFE, Claus \& WIESENTHAL, Helmut. (1984), "Duas lógicas da ação coletiva", in Problemas do Estado capitalista, Rio de Janeiro, Tempo Brasiliense.

POGREBINSCHI, Thamy \& SANTOS, Fabiano. (2011), "Participação como representação: o impacto das conferências nacionais de políticas públicas no Congresso Nacional”. Dados, 54 (3): 259-305.

PREZEWORSKI, Adam \& WALLERSTEIN, Michael. (1988), "Structural dependence of State on capital". The American Political Science Review, 82 (1): 11-30. 
PREZEWORSKI, Adam. (1994), Democracia e mercado: reformas políticas e econômicas no Leste Europeu e na América Latina. Rio de Janeiro, Relume-Dumará.

RADERMACHER, Reiner \& MELLEIRO, Waldeli. (2007), "Mudanças no cenário sindical brasileiro sob o governo de Lula". Nueva Sociedad, 211: 124-143

RAMALHO, José \& RODRIGUES, Iram (2010), "Sindicato, crise econômica e estratégias regionais: novas dimensões da participação política no ABC Paulista”. Caderno CRH, 23 (59): 339-351.

RODRIGUES, Leôncio. (1990), Partidos e sindicatos. São Paulo, Ática.

. (1991), "As tendências políticas na formação das centrais sindicais", in Armando Boito (org.), O sindicalismo brasileiro nos anos 80, Rio de Janeiro. Paz e Terra.

. (2002), Destino do sindicalismo. São Paulo, Edusp.

SANTANA, Marco \& BRAGA, Ruy. (2009), "O Pêndulo Oscilante: sociologia do trabalho e movimento sindical no Brasil”. Caderno CRH, 22 (56): 297-309.

. (1981), "Interest intermediation and regime governability in contemporary Western Europe and North America”, in S. Berger (org.), Organizing interests in Western Europe: pluralism, corporatism and the transformation of politics, Cambridge, Cambridge University Press.

. (1982), "Reflections on where the theory of corporatism has gone and where the praxis of neo-corporatism may be going", in G. Lehmbruch e P. Schmitter (orgs.), Patterns of corporatist policy-making. Londres, Sage.

. (1983), "Democratic theory and neocorporatist practice". Social Research, 50 (4): 885-928.

SIAROF, Alan. (1999), "Corporatism in 24 industrial democracies: meaning and measurement". European Journal of Political Research, 36: 175-205.

SILVA, Roberto. (2008), "Liberalismo e democracia na sociologia política de Oliveira Vianna”. Sociologias, 10 (20): 238-269.

WALLERSTEIN, Michael. (1989), "A centralização sindical e dependências face ao comércio: as origens do corporativismo democrático". Dados, 32: 42-73. 


\section{NOVOS RUMOS DO SINDICALISMO NO BRASIL}

\author{
Alexandre Sampaio Ferraz
}

Palavras-chaves: Corporativismo; Sindicalismo; Instituições políticas; Democracia.

O objetivo deste artigo é resgatar o debate sobre os rumos do corporativismo no Brasil após a redemocratização e avaliar o impacto das mudanças institucionais recentes para o sistema de intermediação de interesse. A retomada da abordagem corporativista na literatura internacional permite um contraponto para o debate interno ao recolocar a importância das dimensôes organizacionais e de "modo de tomada de decisão" para caracterizar o corporativismo como sistema de intermediação de interesses. A partir dessa leitura, o trabalho aponta para o fortalecimento da estrutura sindical, particularmente das organizações de cúpula, e para a multiplicação e a consolidação de diversas arenas tripartite, responsáveis pela definição de temas importantes da política pública. Esses novos traços parecem aproximar cada vez o modelo brasileiro do tipo societário de corporativismo, em oposição ao pluralismo.

\section{NEW DIRECTIONS FOR BRAZILIAN UNIONISM}

\author{
Alexandre Sampaio Ferraz \\ Keywords: Corporatism; Unionism; \\ Political institutions; Democracy.
}

The purpose of this article is to rescue the debate about the direction of corporatism in Brazil after the democratization, as well as to assess the impact of the recent institutional changes on the system of interest intermediation. The resumption of the corporatist approach on the international literature allows for a counterpoint to the internal debate, as it reinforces the importance of the organizational dimensions and the "mode of decision making" to characterize the corporatist interest intermediation. The argument points to the strengthening of the trade union structure, particularly of its top organizations, and to the multiplication and consolidation of several tripartite arenas responsible for the definition of important issues of public policy. These new traces seem to place the Brazilian model of corporatism closer to the "societal" type, as opposed to pluralism.

\section{NOUVELLES ORIENTATIONS POUR LE SYNDICALISME BRÉSILIEN}

\author{
Alexandre Sampaio Ferraz \\ Mots-clés: Corporatisme; Syndicalisme; \\ Institutions politiques; Démocratie.
}

Le but de cet article est de récupérer le débat à propos des différentes orientations du corporatisme au Brésil qui a eu lieu après la démocratisation ainsi que d'évaluer l'impact des changements institutionnels récents pour le système d'intermédiation d'intérêts. La répétition de l'approche corporatiste dans la littérature internationale permet un contrepoint au débat interne en redonnant de l'importance aux dimensions organisationnelles et au " mode de prise de décision " en vue de caractériser l'intérêt corporatiste comme système d'intermédiation des intérêts. À partir de cette interprétation, l'étude indique un renforcement de la structure syndicale, particulièrement des organisations dominantes et vers la multiplication et la consolidation de diverses arènes tripartites, responsables de la définition de thèmes importants de la politique publique. Ces nouveaux propos semblent rapprocher davantage le modèle brésilien du genre sociétaire de corporation en opposition au pluralisme. 